\title{
Role of oral misoprostol, rectal misoprostol and intramuscular 15- methyl-PGF2 $\alpha$ for prophylaxis of postpartum haemorrhage
}

\author{
Santvana Pandey*
}

Department of Obstetrics and Gynecology, Kasturba Hospital, Delhi, India

Received: 11 July 2017

Accepted: 24 July 2017

\section{*Correspondence:}

Dr. Santvana Pandey,

E-mail: dr.pandey1@gmail.com

Copyright: (C) the author(s), publisher and licensee Medip Academy. This is an open-access article distributed under the terms of the Creative Commons Attribution Non-Commercial License, which permits unrestricted non-commercial use, distribution, and reproduction in any medium, provided the original work is properly cited.

\begin{abstract}
Background: Postpartum haemorrhage (PPH) is the most common cause of maternal mortality. Approximately $28 \%$ of maternal deaths worldwide are due to haemorrhage, mostly in the postpartum period. The WHO estimates that of the 303,000 maternal deaths occurring every year, 45,000 takes place in India, where two third of maternal deaths occur after delivery, PPH being the most common cause of death (29.6\%). This study compared oral misoprostol, rectal misoprostol and intramuscular 15methyl-PGF2 $\alpha$ for prophylaxis of postpartum haemorrhage in terms of various outcomes such as drop in $\mathrm{Hb}$ concentration after delivery, the amount of blood loss during delivery and duration of third stage of labour.

Methods: Randomized comparative trial in 1:1:1 ratio of oral misoprostol, rectal misoprostol and IM 15methylPGF2 $\alpha$ groups of 300 low risk pregnant women (with singleton pregnancy and $\geq 28$ weeks gestation age) who underwent normal vaginal delivery at Kasturba hospital during 1 year period.

Results: The mean blood loss was significantly less in IM 15methyl-PGF2 $\alpha$ group as compared to oral and rectal misoprostol groups. Incidence of PPH was least in IM 15methyl-PGF2 $\alpha$ group as compared to oral and rectal misoprostol groups but the difference observed was not statistically significant. Maximum cases with $\mathrm{Hb}$ drop $>1$ $\mathrm{gm} / \mathrm{dl}$ were present in the rectal misoprostol group.

Conclusions: IM 15methyl-PGF2 $\alpha$ was found to be most effective and rectal misoprostol was found to be least effective for prophylaxis of PPH. Gastrointestinal side effects like nausea, vomiting and diarrhoea were significantly higher in the IM 15methyl-PGF2 $\alpha$ group, however it had much lower incidence of shivering and pyrexia.
\end{abstract}

Keywords: 15 methyl-PGF2 $\alpha$, Misoprostol, Oxytocin, Postpartum haemorrhage, Uterine Atony

\section{INTRODUCTION}

Postpartum haemorrhage is the most common cause of maternal mortality and accounts for one quarter of maternal deaths worldwide. Approximately $28 \%$ of maternal deaths worldwide are due to haemorrhage, mostly in the postpartum period. Most maternal deaths due to PPH occur in developing countries in settings where there are no birth attendants or where birth attendants lack the necessary skills or equipment to prevent PPH and shock. To improve the maternal mortality ratio further from $\sim 174$ per 100,000 live births in 2015 , we have to put focussed attention to confronting the problem of PPH in India. ${ }^{1,2}$

Despite safe motherhood activities since 1987, women are still dying in childbirth. Women living in low resource settings are most vulnerable due to concurrent disease, poverty, discrimination and limited access to health care. Indeed $99 \%$ of maternal deaths occur in developing countries that have an inadequate transport system, limited access to skilled caregivers and 
emergency obstetric services. ${ }^{3}$ The WHO estimates that of the 303,000 maternal deaths occurring every year, 45,000 or $15 \%$ take place in India, where two third of maternal deaths occur after delivery, PPH being the most common cause of death $(29.6 \%)^{1,2,4}$

Misoprostol is a PGE1 analogue that is marketed as tablets, does not require special storage condition and is known to have a shelf life of several years. Misoprostol is a potent uterotonic agent and is therefore acquiring clinical applications in the induction of abortion, cervical priming and induction of labour with or without pretreatment with mifepristone (RU486). Misoprostol has no known drug interactions and does not induce the hepatic enzyme systems. ${ }^{5}$

Absorption of misoprostol and misoprostol acid is extremely rapid, being detected in the circulation within two minutes of its oral ingestion. ${ }^{6,7}$ Its effect on postpartum uterus has also been shown to be rapid. Rectal misoprostol is associated with lower peak levels and a reduction in adverse effects compared with oral routes. ${ }^{8}$ Misoprostol may be an alternative to conventional standard oxytocin drug for the prevention of atonic PPH in low risk women. ${ }^{9}$

Another prostaglandin which has been studied in prophylaxis of PPH is 15 methyl-PGF2 $\alpha$. It is 10 times more potent than its natural form and is able to resist enzymatic degradation. ${ }^{10}$ It is an expensive drug, not stable at room temperature and needs refrigeration for storage. A single IM injection of prostin 15M (15methylPGF $2 \alpha$ ) is absorbed rapidly and produces increased tone of the uterus, which is sustained for a period of 5 to 7 hours. ${ }^{11-13}$

In a study of Bhattacharya et al it was concluded that a single $125 \mathrm{mcg}$ injection of prostin $15 \mathrm{M}$ significantly reduced the risk of postpartum bleeding in women during third stage of labour. The small dose of prostin $15 \mathrm{M}$ is well tolerated by all patients. ${ }^{13-17}$

Some trials compared injectable prostaglandins with conventional uterotonic. The trials were heterogeneous and reliable estimates of outcomes were not possible. The injectable prostaglandins were associated with less blood loss, a shorter duration of third stage of labour, more vomiting, diarrhoea and abdominal pain than conventional uterotonic. In 2006, Nellore et al in a randomized study compared the efficacy and side effects of $400 \mathrm{mcg}$ rectal misoprostol with $125 \mathrm{mcg}$ of $15 \mathrm{methyl}-$ PGF2 alpha in the prevention of PPH. ${ }^{18}$

This study focussed on Indian scenario local to walled city of Delhi, with cases having lower mean age due to usually early marriage and early child bearing practices prevalent in vicinity as well as it made three leg comparisons among prostaglandins for prophylaxis of $\mathrm{PPH}$, so far not studied. This study compared oral misoprostol, rectal misoprostol and 15methyl-PGF2 $\alpha$ for prophylaxis of postpartum haemorrhage in terms of various outcomes.

\section{METHODS}

This prospective randomized comparative trial was conducted at the labour room, department of obstetrics and gynaecology, Kasturba hospital, Delhi, India during 1 year period from January 2007 to December 2007. Kasturba Hospital is a 450 bedded hospital, focusing on women and child health. Around 350 beds are exclusively for department of obstetrics and gynaecology and it has 12000 deliveries per year.

Randomized comparative trial in a 1:1:1 ratio of oral misoprostol (600mcg), rectal misoprostol $(600 \mathrm{mcg})$ and IM 15 methyl-PGF2 $\alpha(125 \mathrm{mcg})$ groups of 300 low risk pregnant women (primigravidas or multigravidas with singleton pregnancy and $\geq 28$ weeks gestation age) who underwent normal vaginal delivery at Kasturba hospital during 1 year period from January 2007 to December 2007.

\section{Inclusion criteria}

- Singleton pregnancies in labour in whom vaginal delivery is anticipated

- Gestational age $\geq 28$ weeks.

\section{Exclusion criteria}

- previous caesarean section

- $\quad$ scheduled caesarean section

- patients with high risk factors for PPH, as these patients are more likely to need additional uterotonic- grand multiparty, multiple gestation, $\mathrm{Hb}<$ $8 \mathrm{~g} / \mathrm{dl}$, history of ante partum haemorrhage in present pregnancy, history of manual removal of placenta in previous pregnancy

- Preeclampsia

- Pregnancy associated with medical disorders like bronchial asthma, diabetes mellitus, seizures, cardiac disorder

- Hypersensitivity to Prostaglandins. ${ }^{19}$

Patients who fulfilled the inclusion criteria were explained about the procedure and written informed consent was taken.

When vaginal delivery was imminent, right mediolateral episiotomy was given routinely in all primigravidas at crowning of foetal head. A set of opaque, sequentially numbered sealed envelope were stored in the nursing station of the labour room and indicated the method of treatment of third stage of labour to which the women were allocated.

Randomized administration of oral misoprostol, rectal misoprostol and intramuscular 15 methyl-PGF2 $\alpha$ was 
done at the time of delivery of anterior shoulder of the baby. It was followed by the delivery of rest of the body of the baby, cord being clamped and cut, and the baby was handed over to the paediatrician and weight of the baby was recorded.

The placenta was delivered by controlled cord traction (Brandt Andrew's method). Steady suprapubic pressure was applied to lift the uterus upwards and somewhat backwards to apply the countertraction. The clamp placed on the cord at the vulva was held in the right hand and a constant traction was applied downwards. The pressure exerted by the 2 hands in opposite direction was equal, to keep the position of the uterus unaltered. The controlled cord traction was maintained until placenta was visible at the vulva. Both hands were used to complete the delivery of the placenta and the membranes as the placenta was expelled from the vulval orifice. The placenta was kept in a kidney tray and carefully examined for completeness.

Immediately after the delivery, linen soiled with amniotic fluid was removed, a fresh disposable yellow plastic bag was placed under the patient and a sterile pan was applied against the patient's buttocks to collect all blood until 1 hour after delivery.

The episiotomy, if given, was stitched in layers. The pads, plastic bag and the pan were removed. The vulva and perineum were covered with a fresh sterile pad. The blood in the bed pan along with blood stained sanitary pads and blood contained in plastic bags were weighed (gm). The known dry weight of these items was subtracted to give the approximate volume of blood in $\mathrm{ml}$ $(1 \mathrm{ml}=1.05 \mathrm{gm}$ approximately $)$.

In case of PPH, type of PPH was noted by feeling the uterine tone and contractility. If uterus was flabby (atonic $\mathrm{PPH}$ ) quick bimanual uterine massage was given so that it began to contract and additional oxytocin in the form of $10 \mathrm{IU}$ oxytocin in $500 \mathrm{ml}$ ringer lactate and/or IV 0.25 mg methyl ergometrine were given if patient bled continuously.

Blood transfusion was given as and when required. If the uterus was well contracted and retracted (traumatic PPH) vaginal tears were inspected using Sim's speculum and anterior vaginal wall retractor and cervical exploration was done using 3 sponge holders after exposing the cervix followed by suturing of the tears. These cases were excluded from the study.

Vitals of the patient were carefully monitored including half hourly pulse rate charting and BP charting. Variables concerning labour including duration of first stage (in hours), second stage (in minutes), and third stage (in minutes) were recorded.

Variables concerning delivery such as need for additional uterotonic and BT were noted. The side effects of the drugs like nausea, vomiting, diarrhoea, shivering and pyrexia were noted. Patients were discharged 2 days after the delivery and were called after 12 weeks postpartum to enquire about delayed PPH and secondary infection like fever, lower abdomen pain, any discharge per vaginum.

Outcomes measured were categorised as

\section{Primary outcome}

- Amount of blood loss during delivery (ml) [third stage of labour]

- Postpartum drop in Maternal $\mathrm{Hb}(\mathrm{g} / \mathrm{dl}$ ). (Maternal $\mathrm{Hb}$ concentration measured at the time of admission and repeated 24 hours after delivery)

- Duration of third stage of labour (from placental separation to expulsion of placenta)

\section{Secondary outcomes}

- Need for additional uterotonic

- Need for blood transfusion

- Side effects until 1 hour after delivery which included nausea, vomiting, diarrhoea, shivering and pyrexia

- Incidence of secondary infection and delayed PPH.

\section{RESULTS}

A total number of 300 patients participated in the study. All patients had normal vaginal delivery.

\section{Patients characteristics}

Patient characteristics in terms of Age, Parity, Period of Gestation, and Birth Weight of baby were recorded. The characteristics were similar between the three treatment groups (Table 1).

\section{Primary outcomes}

Of the 300 cases, 33 cases had blood loss more than $500 \mathrm{ml}$. The incidence of PPH was highest in rectal misoprostol group and lowest in the IM 15methyl-PGF2 $\alpha$ group. However, the differences were not statistically significant $(\mathrm{P}$ value $=0.078)($ Table 2$)$.

In the present study, 121 patients of the total 300 patients had $\mathrm{Hb}$ conc. before delivery between $10-11 \mathrm{~g} / \mathrm{dl}$, only 17 patients had $\mathrm{Hb}$ conc. before delivery between $09-10 \mathrm{~g} / \mathrm{dl}$ and remainder 162 patients had $\mathrm{Hb}$ conc. before delivery greater than $11 \mathrm{~g} / \mathrm{dl}$. Mean Hb conc. before delivery in all the 3 groups was comparable (11.38 vs. 11.549 vs. $11.483 \mathrm{~g} / \mathrm{dl}$ in oral misoprostol group, rectal misoprostol group and IM 15methyl-PGF2 $\alpha$ group respectively, $\mathrm{p}=0.422$ ). Mean $\mathrm{Hb}$ concentration 24 after delivery was also found to be comparable in all the 3 groups (11.001 vs. 10.766 vs. $10.990 \mathrm{~g} / \mathrm{dl}$ in oral misoprostol group, rectal misoprostol group and IM 15methyl-PGF2 $\alpha$ group respectively, $\mathrm{p}=0.179$ ) $($ Table 3$)$. 
Table 1: Distribution of cases according to patient characteristics.

\begin{tabular}{|llll|}
\hline Characteristic & Oral misoprostol & Rectal misoprostol & IM 15methyl-PGF2 $\alpha$ \\
\hline Age 15-20 years & $20 \%$ & $19 \%$ & $19 \%$ \\
\hline Age 20-25 years & $40 \%$ & $41 \%$ & $40 \%$ \\
\hline Age 25-30 years & $34 \%$ & $31 \%$ & $35 \%$ \\
\hline Age 30-35 years & $6 \%$ & $9 \%$ & $6 \%$ \\
\hline Mean Age (years) & 24.66 & 24.63 & 24.46 \\
\hline S.D. Age (years) & 3.98 & 4.20 & 4.17 \\
\hline Parity P0 & $87 \%$ & $85 \%$ & $85 \%$ \\
\hline Parity P1 & $8 \%$ & $8 \%$ & $8 \%$ \\
\hline Parity P2 & $5 \%$ & $7 \%$ & $7 \%$ \\
\hline P.O.G. 28-32 weeks & $4 \%$ & $4 \%$ & $5 \%$ \\
\hline P.O.G. 32-36 weeks & $6 \%$ & $5 \%$ & $4 \%$ \\
\hline P.O.G 36-40 weeks & $90 \%$ & $91 \%$ & $91 \%$ \\
\hline MEAN P.O.G. $(w e e k s)$ & 38.19 & 38.08 & 38.21 \\
\hline S.D. P.O.G. (weeks) & 2.01 & 1.83 & 1.91 \\
\hline Birth weight $<1.5 \mathrm{Kg}$ & $4 \%$ & $5 \%$ & $5 \%$ \\
\hline Birth weight $1.5-2 \mathrm{Kg}$ & $3 \%$ & $2 \%$ & $4 \%$ \\
\hline Birth weight $2-2.5 \mathrm{Kg}$ & $52 \%$ & $35 \%$ & $45 \%$ \\
\hline Birth weight $2.5-3 \mathrm{Kg}$ & $33 \%$ & $50 \%$ & $39 \%$ \\
\hline Birth weight $>3 \mathrm{Kg}$ & $8 \%$ & $8 \%$ & $7 \%$ \\
\hline Mean birth weight $(\mathrm{Kg})$ & 2.5390 & 2.5730 & 2.5590 \\
\hline S.D. birth weight $(\mathrm{Kg})$ & 0.4643 & 0.4343 & 0.4571 \\
\hline
\end{tabular}

Note: POG- Period of Gestation.

Table 2: Amount of blood loss during delivery ( $\mathrm{ml})$.

\begin{tabular}{|c|c|c|c|c|}
\hline Blood loss (ml) & Oral misoprostol & Rectal misoprostol & IM 15methyl-PGF2 $\alpha$ & Total \\
\hline$<500$ & $89 \%$ & $84 \%$ & $94 \%$ & $89 \%$ \\
\hline$\geq 500$ and $<1000$ & $11 \%$ & $16 \%$ & $6 \%$ & $11 \%$ \\
\hline MEAN (ml) & 210.980 & 238.060 & 151.170 & \\
\hline S.D. (ml) & 180.35 & 209.07 & 140.45 & \\
\hline
\end{tabular}

$\chi^{2}$ test $p$ value $=0.078 ;$ ANOVA F test $p$ value $=0.002$

Table 3: Hb concentration (g/dl) before delivery and 24 hours after delivery.

\begin{tabular}{|c|c|c|c|c|c|c|}
\hline \multirow{2}{*}{ Hb (g/dl) } & \multicolumn{2}{|c|}{ Oral misoprostol } & \multicolumn{2}{|c|}{ Rectal misoprostol } & \multicolumn{2}{|c|}{ IM 15methyl-PGF2o } \\
\hline & Before & After & Before & After & Before & After \\
\hline $8-9$ & $0 \%$ & $3 \%$ & $0 \%$ & $9 \%$ & $0 \%$ & $6 \%$ \\
\hline $9-10$ & $5 \%$ & $16 \%$ & $6 \%$ & $27 \%$ & $6 \%$ & $16 \%$ \\
\hline $10-11$ & $41 \%$ & $50 \%$ & $40 \%$ & $31 \%$ & $40 \%$ & $43 \%$ \\
\hline $11-12$ & $37 \%$ & $19 \%$ & $36 \%$ & $28 \%$ & $35 \%$ & $21 \%$ \\
\hline $12-13$ & $15 \%$ & $12 \%$ & $16 \%$ & $5 \%$ & $16 \%$ & $14 \%$ \\
\hline$>13$ & $2 \%$ & $0 \%$ & $2 \%$ & $0 \%$ & $3 \%$ & $0 \%$ \\
\hline Mean (g/dl) & 11.380 & 11.001 & 11.549 & 10.766 & 11.483 & 10.990 \\
\hline S.D. $(g / d l)$ & 0.891 & 0.923 & 0.874 & 1.055 & 0.978 & 1.040 \\
\hline
\end{tabular}

ANOVA F test, $\mathrm{p}$ value (before delivery) $=0.422 ; \chi^{2}$ test $\mathrm{p}$ value (before delivery) $=1.0 ; \mathrm{p}$ value (after delivery) $=0.179 ; \chi^{2}$ test $\mathrm{p}$ value (after delivery) $=0.009$

Of the 300 cases, 64 cases $(21.33 \%)$ had postpartum $\mathrm{Hb}$ drop of $>1 \mathrm{~g} / \mathrm{dl}$. The maximum number of cases with a drop in $\mathrm{Hb}$ conc $>1 \mathrm{~g} / \mathrm{dl}$ was observed in the rectal misoprostol group (37\%).

The difference in drop in $\mathrm{Hb}$ conc $>1 \mathrm{~g} / \mathrm{dl}$ was found to be statistically significant $(\mathrm{p}<0.001)$ between oral misoprostol group and rectal misoprostol group and also, between the rectal misoprostol group and IM 15methylPGF $2 \alpha$ group.

The difference observed in the oral misoprostol and IM 15 methyl-PGF $2 \alpha$ group was not statistically significant $(\mathrm{p}=0.836)$ (Table 4). 
Table 4: Drop in Hb (g/dl) after delivery.

\begin{tabular}{|lllll|}
\hline Hb drop $(\mathrm{g} / \mathrm{dl})$ & Oral misoprostol & Rectal misoprostol & IM 15methyl-PGF2 $\alpha$ & Total \\
\hline$<1 \mathrm{~g} / \mathrm{dl}$ & $86 \%$ & $63 \%$ & $87 \%$ & $78.6 \%$ \\
\hline$\geq 1 \mathrm{~g} / \mathrm{dl}$ & $14 \%$ & $37 \%$ & $13 \%$ & $21.33 \%$ \\
\hline Mean $(\mathrm{g} / \mathrm{dl})$ & 0.4060 & 0.7830 & 0.4930 & \\
\hline S.D. $(\mathrm{g} / \mathrm{dl})$ & 0.7049 & 0.8409 & 0.5435 \\
\hline
\end{tabular}

$\chi^{2}$ test $\mathrm{p}$ value $<0.001 ;$ ANOVA F test, $\mathrm{p}$ value $=0.001$

Table 5: Distribution of cases according to duration of third stage of labour.

\begin{tabular}{|lllll|}
\hline Duration of 3rd stage (min) & Oral misoprostol & Rectal misoprostol & IM 15methyl-PGF2 $\alpha$ & Total \\
\hline$<5$ & $80 \%$ & $81 \%$ & $89 \%$ & $83.33 \%$ \\
\hline $5-10$ & $20 \%$ & $19 \%$ & $11 \%$ & $16.67 \%$ \\
\hline Mean (min) & 4.421 & 4.420 & 4.158 & \\
\hline S.D. (min) & 0.964 & 1.174 & 0.926 & \\
\hline
\end{tabular}

$\chi^{2}$ test $\mathrm{p}$ value $=0.173 ;$ ANOVA F test $\mathrm{p}$ value $=0.115$

The mean duration of 3rd stage of labour (mins) was comparable in all the 3 groups. $(4.421 \pm 0.964$ in oral misoprostol group, $4.420 \pm 1.174$ in rectal misoprostol group, $4.158 \pm 0.926$ in IM 15methyl-PGF2 $\alpha$ group). The difference observed was not statistically significant ( $\mathrm{p}$ value $=0.115)($ Table 5).

\section{Secondary outcomes}

In the present study, of the 300 cases, $33(11 \%)$ required additional uterotonic, only 3 cases $(1 \%)$ required blood transfusion, 69 cases $(23 \%)$ had nausea, 66 cases $(22 \%)$ experienced vomiting, 34 cases $(11.33 \%)$ had diarrhoea, 56 cases $(18.67 \%)$ had shivering, 44 cases $(14.67 \%)$ had pyrexia.

The need for additional uterotonic was the least in the IM 15 methyl-PGF2 $\alpha$ group (6\%) as compared to oral misoprostol group $(11 \%)$ and rectal misoprostol group $(16 \%)$. However, the difference observed was not statistically significant. The difference in need for blood transfusion was not statistically significant ( $p$ value $=0.360$ ).
Minimum cases in the rectal misoprostol group experienced nausea and the difference between rectal misoprostol group and other groups was statistically significant, however insignificant difference was found between IM 15methyl-PGF2 $\alpha$ group and oral misoprostol $(\mathrm{p}=0.117)$.

Vomiting was significantly higher in the IM 15 methylPGF2 $\alpha$ group as compared to the rectal misoprostol group. $(\mathrm{p}=0.001)$ while the difference between oral misoprostol group and rectal misoprostol group and that between oral misoprostol group and IM 15methyl-PGF2 $\alpha$ group was statistically insignificant $(\mathrm{p}=0.089$ and $\mathrm{p}=$ 0.151 respectively).

The incidence of diarrhoea was significantly higher in the IM 15 methyl-PGF2 $\alpha$ group (31\%) as compared to the other 2 groups $(\mathrm{p}<0.001)$.

None of the cases in the IM 15methyl-PGF2 $\alpha$ group had shivering as compared to 35 cases $(35 \%)$ in oral misoprostol group and 21 cases $(21 \%)$ in the rectal misoprostol group. This difference was statistically significant $(\mathrm{p}<0.001)$.

Table 6: Distribution of cases according findings for secondary outcome.

\begin{tabular}{|lllll|}
\hline Secondary outcomes & Oral misoprostol & Rectal misoprostol & IM 15methyl-PGF2 $\alpha$ & Total \\
\hline Additional uterotonic & $11 \%$ & $16 \%$ & $6 \%$ & $11 \%$ \\
\hline Blood transfusion & $1 \%$ & $2 \%$ & $0 \%$ & $1 \%$ \\
\hline Nausea & $23 \%$ & $12 \%$ & $34 \%$ & $23 \%$ \\
\hline Vomiting & $22 \%$ & $12 \%$ & $32 \%$ & $22 \%$ \\
\hline Diarrhoea & $3 \%$ & $0 \%$ & $31 \%$ & $11.33 \%$ \\
\hline Shivering & $35 \%$ & $21 \%$ & $0 \%$ & $18.67 \%$ \\
\hline Pyrexia & $28 \%$ & $16 \%$ & $0 \%$ & $14.67 \%$ \\
\hline Delayed PPH & $0 \%$ & $0 \%$ & $0 \%$ & $0 \%$ \\
\hline Secondary infection & $0 \%$ & $0 \%$ & $0 \%$ & $0 \%$ \\
\hline
\end{tabular}


The incidence of pyrexia was highest in oral misoprostol group (28\%) followed by rectal misoprostol group (16\%) while none of the cases in IM 15methyl-PGF2 $\alpha$ group had pyrexia. The difference in the incidence of pyrexia was significant between both misoprostol groups and IM 15methyl-PGF2 $\alpha$ group $(\mathrm{p}<0.001)$ (Table 6).

\section{DISCUSSION}

Postpartum haemorrhage is the leading cause of maternal mortality in India, accounting for $28 \%$ of all maternal deaths. ${ }^{20}$ In countries in which many women have severe anaemia during pregnancy because of nutritional and environmental factors, even a relatively small reduction of postpartum blood loss could be relevant clinically. The WHO has recommended the IM prophylactic administration of oxytocin in the third stage of labour. However, there are potential problems with use of oxytocin and ergometrine in developing countries (e.g. the need for protection from light, the need for refrigeration and sterile needles and syringes for administration).

Misoprostol offers several advantages over oxytocin or ergometrime, which include a shelf life of several years, stability at high temperature, oral and rectal administration and minimal side effects and that it can be administered to patients who are hypertensive. The rectal route for misoprostol use has been considered as it was expected to have several practical advantages. Gastrointestinal side effects might be reduced; the administration of misoprostol to patients, who are vomiting, unable to take orally, would be possible. ${ }^{21}$

Present study found that IM 15 methyl-PGF2 $\alpha$ was most effective and rectal misoprostol was least effective for prophylaxis of PPH. Gastrointestinal side effects like nausea, vomiting and diarrhoea were significantly higher in the IM 15 methyl-PGF2 $\alpha$ group; however, it had much lower incidence of shivering and pyrexia. Rectal misoprostol had much lower gastrointestinal side effects like nausea, vomiting and diarrhoea as well as much lower incidences shivering and pyrexia as compared to oral misoprostol. This finding could open the possibility of increasing the rectal dose in higher level to achieve greater efficacy without increasing the adverse effect.

\section{Primary outcomes}

\section{Blood Loss during Delivery}

In the present study, mean amount of blood loss was least in the IM 15 methyl-PGF2 $\alpha$ group $(151.170 \mathrm{ml})$ and it was highest in the rectal misoprostol group $(238.060 \mathrm{ml})$ which is comparable to other studies ${ }^{18}$. Oral misoprostol group had mean blood loss of $210.980 \mathrm{ml}$. This difference was statistically significant $(p=0.002)$. The difference observed between oral misoprostol and IM 15 methyl-PGF2 $\alpha$ group was statistically significant $(\mathrm{p}=0.010)$ and difference between rectal misoprostol and
IM 15methyl-PGF2 $\alpha$ group was statistically significant ( $p$ $=0.001)$. However, the difference between oral and rectal misoprostol group was not statistically significant $(\mathrm{p}=$ 0.328).

\section{Incidence of $\mathrm{PPH}$}

Incidence of PPH $(>500 \mathrm{ml})$ was maximum in rectal misoprostol group (16\%) followed by oral misoprostol group (11\%) followed by IM 15methyl-PGF2 $\alpha$ group (6\%) so IM 15methyl-PGF2 $\alpha$ group was most effective in preventing $\mathrm{PPH}$, but the difference observed was not statistically significant. This was not comparable to Nellore $\mathrm{V}$ et al study where PPH occurred in $0.6 \%$ of misoprostol group and $0.5 \%$ of IM 15 methyl-PGF $2 \alpha$ group $^{18}$ nor was it comparable to Bamigboyee et al study. ${ }^{18,22}$

\section{Postpartum Hb drop}

Mean drop in $\mathrm{Hb}$ in the rectal misoprostol group was $0.7830 \mathrm{gm} / \mathrm{dl}$ which was highest amongst all groups, mean drop in $\mathrm{Hb}$ in the IM 15methyl-PGF2 $\alpha$ group was $0.4930 \mathrm{gm} / \mathrm{dl}$ and in oral misoprostol group was 0.4460 $\mathrm{gm} / \mathrm{dl}$. This difference observed was statistically significant, though the mean $\mathrm{Hb}$ before delivery was comparable in all the three groups. The highest and lowest values of $\mathrm{Hb}$ were present in the rectal misoprostol group which accounted for the highest drop seen in this group. This difference observed may partly be due to the relatively late onset of action of rectal misoprostol as compared to the oral group and parenteral IM 15methyl-PGF2 $\alpha$. Maximum number of cases with $\mathrm{Hb}$ drop $>1 \mathrm{gm} / \mathrm{dl}$ were present in the rectal misoprostol group (37\%) followed by oral misoprostol group (14\%) followed by IM 15 methyl-PGF2 $\alpha$ group (13\%). The difference was statistically significant between oral and rectal misoprostol groups $(\mathrm{p}<0.001)$ and between rectal misoprostol and IM 15methyl-PGF $2 \alpha$ group $(\mathrm{p}<0.001)$ but not between oral misoprostol and IM 15methylPGF2 $\alpha$ group.

\section{Duration of $3^{\text {rd }}$ state of labour}

In the present study, all the 3 groups were comparable with respect to mean durations of 1 st and 2 nd stage of labour. The mean duration of 3rd stage of labour was also comparable in all the three groups, $\mathrm{p}=0.115$ (4.42 $\mathrm{min}$ oral misoprostol group, $4.420 \mathrm{~min}$ rectal misoprostol group, $4.158 \mathrm{~min}$ in IM 15 methyl-PGF2 $\alpha$ group). This was comparable to Nellore $\mathrm{V}$ et al study and other studies $^{23-26}$.

\section{Secondary outcome}

\section{Need for additional uterotonic}

In the present study, it was observed that only $6 \%$ of cases in the IM 15methyl-PGF2 $\alpha$ group required additional uterotonic as against $16 \%$ cases in rectal 
misoprostol group and $11 \%$ in oral misoprostol group. Thus, rectal misoprostol was associated with an increased need for additional uterotonic in the current study. This may partially be due to relatively late onset of action of rectal misoprostol. However, the difference was statistically insignificant $(\mathrm{p}=0.078)$, this could be explained by the fact that additional uterotonic were given only when blood loss was $>500 \mathrm{ml}$, the incidence of which was also statistically insignificant in the 3 groups.

\section{Need for BT}

In the present study, no woman in the IM 15methylPGF $2 \alpha$ group required BT as against 1 case in oral misoprostol group and 2 cases in rectal misoprostol group which was statistically insignificant $(\mathrm{p}=0.360)$.

\section{Nausea}

In the present study incidence of nausea was highest in the IM 15methyl-PGF2 $\alpha$ group followed by oral misoprostol group and least in rectal misoprostol group. The difference was statistically significant between rectal misoprostol and IM 15methyl-PGF2 $\alpha$ group ( $<<0.001)$ and also between oral misoprostol and rectal misoprostol group $(\mathrm{p}=0.041)$. The findings were comparable to $\mathrm{El}$ Refaey et al study ${ }^{27}$.

\section{Vomiting and diarrhoea}

Incidence of vomiting and diarrhoea was also highest in the IM 15methyl-PGF2 $\alpha$ group followed by oral misoprostol group, followed by rectal misoprostol group.

\section{Shivering and pyrexia}

Highest incidence of shivering and Pyrexia was observed in the oral misoprostol group followed by rectal misoprostol group and no patient in the IM 15methylPGF $2 \alpha$ group had shivering or pyrexia. The lack of sharp absorption peak might be responsible for the lower incidence of shivering and pyrexia observed in the rectal misoprostol group. This finding could open the possibility of increasing the rectal dose in higher level to achieve greater efficacy without increasing the adverse effect.

\section{ACKNOWLEDGMENTS}

Authors would like to thank all the specialists, colleagues and staff at the Kasturba Hospital, especially the team for the support during study. Author would like to thank Dr Mala Shukla for her intellectual guidance and support through this study. Author would also record the thanks and gratitude to the patients who consented to recruitment for this study

\section{Funding: No funding sources Conflict of interest: None declared}

Ethical approval: The study was approved by the Institutional Ethics Committee

\section{REFERENCES}

1. Alkema L, Chou D, Hogan D. Global, regional, and national levels and trends in maternal mortality between 1990 and 2015, with scenario-based projections to 2030: a systematic analysis by the UN Maternal Mortality Estimation Inter-Agency Group. Lancet. 2016;387:462-74.

2. Say L, Chou D, Gemmill A, Tunçalp Ö, Moller AB, Daniels $\mathrm{J}$ et al. Global causes of maternal death: a WHO systematic analysis. Lancet Global Health. 2014;2(6):e323-33.

3. Abou ZC. Antepartum and Postpartum haemorrhage. In Murray CJL, Lopez AD, eds. In: Health dimensions of sex and Reproduction. Boston:Harvard University Press; 1998:172-8.

4. Lynn P, Freedman RJ, Waldman H de Pinho, Wirth ME. Who's got the power? Transforming health system for women and children. UN Millennium Task Force on child health and maternal health. 2005:77-95.

5. Foote EE, Lee DR, Karim A. Disposition of misoprostol and its active metabolite in patients with normal and impaired renal function. $\mathbf{J}$ Clin Pharmacol. 1995;35:384-9.

6. Tango S, Schweer H, Seyberth HW. Pharmacokinetics of different routes of administration of misoprostol. Hum Reprod. 2002;17:332-6.

7. Zieman M, Fong SK, Benowitz NL. Absorption kinetics of misoprostol with oral or vaginal administration. Obstet Gynecol. 1997;90:88- 92.

8. Khan RU, El- Refaey H. Pharmacokinetics and adverse effect profile of rectally administered misoprostol in the third stage of labour. Obstet Gynecol. 2003;101(5):968-74.

9. El- Rafaey, Nooh R, O’ Brien P, Abdalla M, Geary M, Walder J, Rodeck C. the misoprostol third stage of labour study: a randomized controlled comparison between orally administered misoprostol and standard management. BJOG. 2000;107(9):1104-10.

10. Devi PK, Sutaria VD, Raghavan KS. Prophylactic use of 15(s) 15methyl-PGF2 $\alpha$ for control of postpartum bleeding. Acta Obstet Gynecol Scand. 1988;145 suppl:s7-8.

11. Hayashi RH, Castillo MS, Noah ML. Management of severe PPH due to uterine atony using an analogue of PGF2 $\alpha$. Obstet Gynecol. 1981;58(4):426- 9.

12. Corson SL, Bolongnese RJ. Postpartum uterine atony treated with prostaglandins. Am J Obstet Gynecol. 1977;129(8):918-9.

13. Bhattacharya P, Devi PK, Jain S. Prophylactic use of 15(s) 15methyl-PGF2 $\alpha$ by intramuscular route for control of postpartum bleeding- A comparative trial with methyl ergometrine. Acta Obstet Gynecol Scand. 1988;145 suppl:S13-5. 
14. Kerekes L, Domokos N. The effect of PGF2 $\alpha$ on 3rd stage of labour. Prostaglandins. 1979;18:161-6.

15. Friedman MA. Manufacturer's warning regarding unapproved uses of misoprostol. N Engl J Med. 2001;344:61.

16. Barik S, Datta S, Gupta K. misoprostol: pharmacology in Barik S, Dutta S, Gupta K,e ds. In: Misoprostol in obstetrics and gynecology. New Delhi. Jaypee Brothres; 2003:8-15.

17. Davies NM, Longstreth J, Jameli F. Misoprostol therapeutic revisited. Pharmacotherapy. 2001;21(1):60-73.

18. Nellore V, Mittal S, Dadhwal V. Rectal misoprostol vs 15 methyl-PGF $2 \alpha$ for the prevention of PPH. Int J Gynecol Obstet. 2006;94:45-6.

19. Tripathi KD. In: Essentials of medical pharmacology. 4th ed. Delhi. Jaypee brothers;2000:312-20.

20. Chandiok N, Dhillon BS, Datey S, Mathur A, Saxena NC. Oral misoprostol for prevention of PPH by paramedical workers in India. Int J Gynecol Obstet. 2006;94:149-55.

21. Bugalho A, Daniel A, Faundes A, Cunha $M$. misoprotol for prevention of PPH. Int J Gynecol Obstet. 2001;73:1-6.

22. Bamigboyee AA, Hofmeyr GJ, Merell DA. Rectal mioprostol in the prevention of $\mathrm{PPH}$ : a placebo controlled trial. Am J Obstet Gynecol. 1998; 179:1043-6

23. Caliskan E, Maydanli M, Dilbaz B, Aykan B, Sonmeaer M, Haberal A. is rectal misoprostol really effective in the treatment of 3rd stage of labour? A randomized controlled trial. Am J Obstet Gynecol. 2002;187(4):1038-45.

24. Zachariah ES, Naidu M, Seshadri L. Oral misoprostol in the 3rd stage of labour. Int J Gynecol Obstet. 2006;92:23-6.

25. Prata N, Hamza S, Gypson R, Nada K, Vahidnia F, Polls H. misoprostol and active management of 3rd stage of labour. Int J Gynecol Obstet. 2006;94:14955.

26. Bamigboyee AA, Merrell DA, Hofmeyr DJ, Mitchell R. randomized comparison of rectal misoprostol with syntometrine for management of 3rd stage of labour. Acta Obstet Gynecol. 1998;77(2):178- 81.

27. El Refaey H, O'Briem P, Morafa W, Walder J, Rodeck C. Use of oral misoprostol in the prevention of PPH. Br J Obstet Gynecol. 1997;140(3):336-9.

Cite this article as: Pandey S. Role of oral misoprostol, rectal misoprostol and intramuscular 15methyl-PGF2 $\alpha$ for prophylaxis of postpartum haemorrhage. Int J Reprod Contracept Obstet Gynecol 2017;6:3796-3803. 